\title{
Stroke Prevention and Sodium Restriction
}

\author{
Norman RC Campbell, J David Spence
}

Can. J. Neurol. Sci. 2008; 35: 278-279

Stroke prevention is extremely cost-effective. The Ontario Task Force for the Coordinated Stroke Strategy for Ontario received from Dr. Muhammad Mamdani of the Institute for Clinical Evaluative Sciences the estimate that stroke prevention is approximately ten times more cost-effective than treating acute stroke with tPA. ${ }^{1}$ Hackam and Spence ${ }^{2}$ have calculated that in the highest-risk patients it would be possible to reduce the risk of stroke by more than $90 \%$ by a combination of interventions (including blood pressure control, smoking cessation, diet, treatment of diabetes, lipid-lowering therapy, and for patients in whom it is indicated, anticoagulation for atrial fibrillation or carotid endarterectomy). Dr Mukul Sharma (personal communication) has shown that stroke prevention is a dominant strategy in health economic terms; i.e. that it improves outcomes while reducing net costs. Effective control of hypertension has the potential to reduce stroke by half. ${ }^{3,4}$ Because hypertension is so prevalent, it accounts for the greatest population attributable risk for stroke, and thus represents the greatest opportunity to reduce stroke.

On Oct 25, 2006, 17 major Canadian health care, scientific and non-governmental organizations including the Canadian Stroke Network announced an endorsed policy statement calling on the government and the food sector to reduce sodium additives to food. The call to action was closely followed by the Government of Canada announcing the formation of an intersectoral work group to oversee the reduction in sodium additives to food. Neurologists and neuroscientists may wonder about the reasons for a focus on dietary sodium and what the benefits are for Canadians.

Many health care professionals are aware that high dietary intake of sodium leads to increased blood pressure and that some patients are more susceptible.5,6 However, some may be confused by literature sponsored by the food processors indicating that the changes in blood pressure are small, that only certain types of people are affected, and that interventions to reduce dietary sodium are relatively ineffective. ${ }^{7}$ This commentary is to explain the importance of reducing dietary sodium for the health of Canadians and to explain why health care professionals should support this effort.

For an adult, Health Canada recommends that sodium intake of 1200-1500 mg per day is 'adequate intake' and that $2300 \mathrm{mg}$ per day is the 'tolerable upper limit' for health. ${ }^{6}$ Currently Canadians consume about $3500 \mathrm{mg}$ of sodium a day. An 1800 $\mathrm{mg} /$ day reduction in dietary sodium reduces blood pressure in hypertensive patients by about $5 / 3 \mathrm{mmHg}$, with more aggressive dietary sodium reduction resulting in even greater blood pressure lowering. ${ }^{5}$ A reduction of $1800 \mathrm{mg}$ sodium per day is estimated to reduce the prevalence of hypertension in Canada by $30 \%$ and to prevent 1 in 7 stroke deaths, 1 in 11 coronary deaths, and 1 in 14 deaths from any cause in hypertensive patients. ${ }^{8,9}$ Further, this reduction in dietary sodium would result in a reduction in blood pressure in normotensive Canadians of $2 / 1 \mathrm{mmHg}$ with an estimated reduction of 1 in 17 stroke deaths, 1 in 25 coronary deaths, and 1 in 33 deaths. ${ }^{9}$

Approximately $80 \%$ of dietary sodium is added to food in processing, with less than $10 \%$ being present in unprocessed food. ${ }^{6}$ As most Canadians eat a substantial amount of food that is processed or bought at restaurants, most are not aware they are eating unhealthy amounts of sodium..$^{10,11}$ By itself, advice to patients to reduce sodium intake is relatively ineffective ${ }^{12}$ because sodium sources are both ubiquitous and not apparent to the consumer. Therefore the effort to reduce dietary sodium intake will be most effective if the amount of sodium added during the processing of food can be reduced. It is important that the public understand the need to select lower sodium foods. Health care professionals should provide brief interventions and ensure they have literature such as Canada's Food Guide (www.hc-sc.gc.ca/fn-an/foodguide-aliment/index_e.html) to educate patients on reduced dietary sodium as part of a healthy lifestyle. Gradual reductions in sodium (10\%) over six weeks or more are generally not noticed by patients. More rapid reductions in dietary sodium may be unpalatable because of an acquired taste. Key educational points for patients are provided in the table; more details can be found at www.hypertension.ca/bpc.

By using a multifaceted approach of reducing sodium additives to food and educating the population, Finland reduced dietary sodium intake by $40 \% .{ }^{13}$ The Canadian initiative expects to reduce dietary sodium intake to less than the upper limit by 2020.

From the Departments of Medicine, Community Health Sciences, Pharmacology and Therapeutics (NRCC), University of Calgary, Libin Cardiovascular Institute, Calgary, Alberta; Robarts Research Institute (JDS), London, Ontario, Canada.

Received December 20, 2007. Final Revisions Submitted January 14, 2008. Reprint requests to: Norman RC Campbell, Departments of Medicine, Community Health Sciences, and of Pharmacology and Therapeutics, University of Calgary, Libin Cardiovascular Institute, 3330 Hospital Drive NW, Calgary, T2N 4N1, Alberta, 
Table: Advice for patients on how to reduce dietary sodium*

Eat more fresh foods, especially fruit and vegetables

Purchase processed foods with low salt claims on labels, or brands with the lowest percentage of daily sodium intake on the food label Purchase less heavily salted foods (avoid pickled foods, olives, salted crackers or snacks, processed meats, etc).

Rinse canned foods with water before eating.

Use less salt in home cooking, and no added salt at the table

* with permission of Blood Pressure Canada

\section{REFERENCES}

1. Joint Strategy Working Group. Towards an integrated stroke strategy for Ontario. Ontario Ministry of Health and Long-term Care and the Heart \& Stroke Foundation of Ontario; 2000.

2. Hackam DG, Spence JD. Combining multiple approaches for the secondary prevention of vascular events after stroke. A quantitative modeling study. Stroke. In press. 2007.

3. Spence JD. Cerebral consequences of hypertension. In: Laragh JH, Brenner B, editors. Hypertension: pathophysiology, diagnosis, and management. 2nd ed. New York: Raven Press; p. 1995. 741-53.

4. MacMahon S, Peto R, Cutler J, Collins R, Sorlie P, Neaton J, et al. Blood pressure, stroke, and coronary heart disease. Part 1. Prolonged differences in blood pressure: prospective observational studies corrected for the regression dilution bias. Lancet. 1990; 335(8692):765-74.

5. He FJ, MacGregor GA. Effect of longer-term modest salt reduction on blood pressure. Cochrane Database of Systematic Reviews. 2004. Issue 1. Art. No.: CD004937. DOI: 10.1002/14651858. CD004937.

6. Panel on Dietary Reference Intakes for Electrolytes and Water, Standing Committee on the Scientific Evaluation of Dietary Reference Intakes. Dietary reference intakes for water, potassium, sodium, chloride and sulfate. Washington, D.C. National Academies Press; 2004. 1-640.
7. MacGregor GA, Sever PS. Salt - overwhelming evidence but still no action: can a consensus be reached with the food industry? BMJ. 1996; 312(7041): 1287-9.

8. Joffres MR, Campbell NRC, Manns B, Tu K. Estimate of the benefits of a population-based reduction in dietary sodium additives on hypertension and its related health costs in Canada. Can J Cardiol. 2007; 23(6):437-43.

9. Whelton PK, He J, Appel LJ, Cutler JA, Havas S, Kotchen TA, et al. Primary prevention of hypertension. Clinical and public health advisory from the national high blood pressure education program. JAMA. 2002; 288(15):1882-8.

10. Health Canada. Nutrient value of some common foods. Ottawa, Canada, Canadian Government Publishing, Public Works \& Government Services Canada; 1999. p. 1-55.

11. Garriguet D. Sodium consumption at all ages. Health Reports. 2007; 18(2):47-52.

12. Hooper L, Bartlett C, Smith GD, Ebrahim S. Systematic review of long term effects of advice to reduce dietary salt in adults. BMJ. 2002; 325(7365):628-37.

13. Karppanen H, Mervaala E. Sodium intake and hypertension. Prog Cardiovasc Dis. 2006; 49(2):59-75. 